Vol. 10, Issue 3, Jun 2020, 14005-14018

(C) TJPRC Pvt. Ltd.

\title{
PERFORMANCE OPTIMIZATION AND EMISSION CHARACTERISTICS OF CI ENGINE FUELLED WITH BLENDS OF WASTES CHICKEN FAT BIODIESEL WITH EXHAUST GAS RECIRCULATION
}

\author{
MANJUNATHA $\mathbf{R}^{\mathbf{1}}$, BYREGOWDA $\mathrm{HV}^{\mathbf{2}}$ \& PANDURANGA MURTHY $\mathrm{G}^{\mathbf{3}}$ \\ ${ }^{1}$ Department of Mechanical Engineering, Vivekananda Institute of Technology, Bangalore, India \\ ${ }^{1 \& 2}$ Research Centre, Department of Mechanical Engineering, Ghousia College of Engineering, Ramanagara, India \\ ${ }^{3}$ Department of Engineering Chemistry, Maharaja Institute of Technology, Thandavapura, Mysore, India
}

(Affiliated to Visvesvaraya Technological University, Belagavi, Karnataka, India.)

\begin{abstract}
Demand for fuel and the use of petroleum products are being increased gradually which causes serious problems such as petroleum depletion, energy crisis and environment degradation etc. Consequently, at this juncture, biodiesel is found to be a good alternative and a promising conventional diesel fuel. Subsequently, the application of biodiesel not only fulfilling the gap of energy catastrophe but, also proffers some shortcomings such as high oxides of nitrogen, high fuel consumption and higher density. Therefore, in order to prevail over this problems and reducing exhaust emission, the study has been undertaken to demonstrate the study on Emission Characteristics of a CI Engine fuelled with Wastes Chicken Fat Biodiesel (WCFB) blends with Exhaust Gas Recirculation (EGR). In the study, initially, Biodiesel is obtained from Chicken fat oil as a result of transesterification process. The experiment work was done on a CI-Engine using a biodiesel (trial with variable blends) achieved by Chicken fat oil with Exhaust Gas Recirculation (@30\%). Further, the performance and emission characteristics of all the blends were carried-out and were compared decisively with petro-diesel. The experimental results shows that, the enhanced Performance and Emission characteristics with B20 biodiesel blend and the momentous reduction in NOX emission using Exhaust Gas Recirculation approach was observed. In addition, the thermal efficiency was increased and SFC (Specific fuel consumption) was found to be better in blending fraction of WCF Biodiesel. A noticeable approach on the parameters like, decrease in carbon monoxide reduced unburned hydrocarbon (UBHC) and decreases in nitrogen oxide emissions are attained at the blending fraction of B20 biodiesel when compared with petrodiesel. Hence, there is a significant reduction in CO, UBHC and NOx emission parameters at B20 biodiesel blending ratio coupled with Exhaust Gas Recirculation (EGR) system. However, the EGR level was optimized (30\%) with respect to the performance of CI Engine linking with significant reduction in the emission of NOX, minimum possible smoke, CO, HC emissions and corresponding with brake thermal efficiency.
\end{abstract}

KEYWORDS: Waste Chicken Fat Biodiesel, Performance Optimization, CI Engine \& EGR

Received: Jun 05, 2020; Accepted: Jun 25, 2020; Published: Sep 18, 2020; Paper Id.: IJMPERDJUN20201337

\section{LIST OF SYMBOLS}

BTE: Brake Thermal Efficiency

SFC: Specific Fuel Consumption

CI Engine: Internal Combustion Engine

NOx: Oxides of Nitrogen

CO: Carbon Monoxide

HC: Hydrocarbon 
PM: Particulate matter

UBHC: Unburnt hydrocarbon

EGR: Exhaust Gas Recirculation

WCFB: Wastes Chicken Fat Biodiesel

\section{INTRODUCTION}

Globally, there has been a tremendous increase in the number of industries and automobiles establishing over the last two decades. In the current scenario, the motor vehicle population in India is about one hundred million. Even though the transport sector plays an essential role in the economic development of any country and it brings an unavoidable specter of environmental deterioration along with it. This in particular will be a big problem for developing country like, India where, a potential search for an environmental friendly alternative fuel to diesel for sustainable future with low cost is of great interest. The development of new energy resources has become important agenda in relation to national energy policy [1]. According to estimates of the oil and gas journal, crude oil production is expected to reach a peak in another one decade and from then on, it is eventually going to decrease. With this, the crude oil will be expensive progressively until it becomes unaffordable while putting pressure on the import bill and increasing the import bill deficit [2].

Thus, there is a need to look at other options as far as energy needs are concerned. Based on the recent research, biodiesel has more attractive because of its performance and environmental benefits and the facts that it is eco-friendly, nontoxic and can be made from the renewable resources [3,4]. They have acclaimed to have zero net production of $\mathrm{CO}_{2}$ gas in global context. It has been found that engines running on biodiesel run successfully for longer durations with its significant performance and emission characteristics are quite comparable to that of petroleum based diesel fuel [5-7]. In India, the biodiesel is produced mainly from vegetable oils followed by some biomass residues. But, only limited research is done in the field of biodiesel production from animal fats, waste oils and algal feedstock respectively.

On the whole, the animal fats are co-products generated from the meat and fish industries, and the focus on production of bio-diesel derived from animal fat is still not promoted due to the ethical reasons $[8,9]$. Hence, in order to commercialize the source for the production of biodiesel, the present study has been proposed to achieve biodiesel from Wastes Chicken Fat followed by its optimized parametric features using a CI-Engine coupled with Exhaust Gas Recirculation.

In the waste chicken meat samples, the feather meat contains variable fat contents (4-12\%) and is a throw away material which can be a potential resource for the production of biodiesel. On the other side, environmental waste management can be achieved by utilizing the wastes chicken meat apart from its biodiesel value [10,14]. This can facilitate prospectively to replace the fossil fuels as the prices are ceaselessly increasing in the global market. Besides, the statistical report says that, approximately 800,000 tones of chicken meat is consumed every year, in which 80,000 tones of chicken fat is being generated as waste material and creating serious health problems to the human beings[16-18]. This has aggravated to undertake the objectives of making biodiesel out of animal meet wastes materials for sustainable development [19].

\section{MATERIALS AND METHODOLOGY}

In the present study, the waste chicken fat materials were collected from the authorized Chicken Meat shops, Bengaluru, Karnataka (India). The chemicals used in the biodiesel production were of standard analytical grade purchased from 
authorized Chemical suppliers, Bengaluru. The standard protocols were adopted in the experimental analysis and in order to ascertain the data of the results, the generated results were of executed for three replicates $[14,16]$. The engine test rig was identified to investigate the effect of CI engine with EGR using waste chicken fat biodiesel blends fuelled throughout the load spectrum. The biodiesel blends are prepared by varying the concentration of biodiesel in diesel and the properties are determined based on ASTM [9,17] standards and the same are presented in the Table 2.3. The generated results of the study was subjected for interpretation and statistically analyzed for its significance and ANOVA one way interaction.

\section{Collection of Waste Chicken meat and Extraction of Fat for Biodiesel Production}

Nearly $8-10 \mathrm{~kg}$ of chicken waste sample was collected and subjected for boiling with $1000 \mathrm{ml}$ of water at $100^{\circ} \mathrm{C}$ for about 30 min in a suitable container. After boiling the container was allowed to cool for 60 minutes, then, the boiled sample was subjected for filtration process. After the filtration, the fat content was separated from the water phase using a separating funnel and the properties of Waste Chicken fat sample were evaluated as per the standard procedure (Table 2.2). Finally, the chicken fat contents were obtained (Figure 2.2).

\section{Purification of Fat Sample}

After the extracting fat from waste chicken meat sample, the obtained fat was taken in a clean conical flask in order to remove the excess water present in the fat content by heating at $100^{\circ} \mathrm{C}$. Then, the boiled fat content was allowed to cool for $45 \mathrm{minutes}$ The fat sample was analyzed for its free fatty acid (FFA) content which should be less than $1 \%$ so as to avoid soap formation during the process of biodiesel production [23]. The fatty acid composition of chicken meat fat samples was covered (Table 2.1). Further, the FFA of chicken fat sample was subjected for transesterification.

\section{Transesterification Process of Chicken Fat}

This is the process of converting animal fats or even vegetable oils into fatty acid methyl esters (bio-diesel) in presence of an alcohol and an alkali Methanol is used as an alcohol and $\mathrm{KOH}$ (Potassium Hydroxide) is used as an alkali. In the procedure, $500 \mathrm{~g}$ of purified fat was taken with $1 \mathrm{Wt} \%$ of $\mathrm{KOH}$ and 1:6 oil to methanol molar ratio in a round bottom flask. The experimental container was kept on a hot plate (@1500 rpm) fitted with a magnetic stirrer and heated at $60^{\circ} \mathrm{C}$ for about 90 min. After the process, the mixture was allowed to cool for about $60 \mathrm{~min}$.Then; the mixture was poured in a separating funnel and kept it for the duration of $12 \mathrm{hrs}$. Then, the top layer as biodiesel and the bottom layer as glycerol were separated and the biodiesel obtained was then subjected for washing with warm water in order to remove residual catalyst or soaps. Finally, a clear amber, yellow liquid called purified biodiesel with a viscosity similar to petro-diesel which was maintained in a suitable container for further parametric analysis [13].

\section{Development of Experimental CI Engine Test-Rig}

The engine test rig in principle is a facility used to develop, characterize and evaluate the performance of engines in association with fuel types. A sophisticated engine test rig houses several sensors (or transducers, data acquisition features and actuators) to control the engine state. The experiments were carried out with a test rig components comprising of a double cylinder, four strokes, water cooled CI engine (KIRLOSKAR MAKE) to study the Performance and Emission characteristics of biodiesel blends (B10 B20) obtained from Chicken fat samples without EGR. The figure 2.1illustrates the various parts of the test engine and the test engine was coupled with an eddy current dynamometer to control the engine torque for loading the engine. A high speed computer digital based data acquisition system consisting of a sensor system was used to measure fuel intake, load, speed and BMEP etc. The exhaust emission parameters were measured with AVL di-gas analyzer and AVL 
smoke meter was used for measuring amount of smoke emitted [5].

The experimental tests were carried out at five different levels with an increment of $20 \%$ along the consecutive loads ranging from $0 \%, 20 \%, 40 \%, 60 \%, 80 \%$ and $100 \%$ loads keeping the speed constant at $1500 \mathrm{rpm}$. Initially, the test CI engine was run with neat diesel for 20mins to warm it up before testing other blending fractions. Then, the test was carried for both diesel and biodiesel with respect to the performance and emission parameters. The combustion characteristics for various loads using eddy current dynamometer were measured and corresponding emissions with gas analyzer and smoke meter. The outcome of the experiment was then compared with petro-diesel and the values were recorded [12].

\section{Experimental Design}

The experimental set up with various components in the present study was shown in Figure.2.1 and Figure.2.4 respectively. The experimental work was carried out for the objectives which require an engine test set up adequately instrumented for necessary performance and emission characteristics. The waste Chicken fat oil blends and pure diesel were used to test a TV1 Engine (Kirloskar) of double acting, 4-stroke, water cooled diesel engine having a rated output of $16 \mathrm{HP}$ at $1800 \mathrm{rpm}$ and a compression ratio of 17.5:1. The engine was coupled with an eddy current dynamometer to apply different engine loads. The emission from the engine was studied at different engine loads, thereafter, when the engine reach stabilized working condition, emissions like carbon monoxide, hydrocarbon, nitrous oxide and exhaust gas temperature (EGT) were measured using a smoke meter and an exhaust gas analyzer [17].

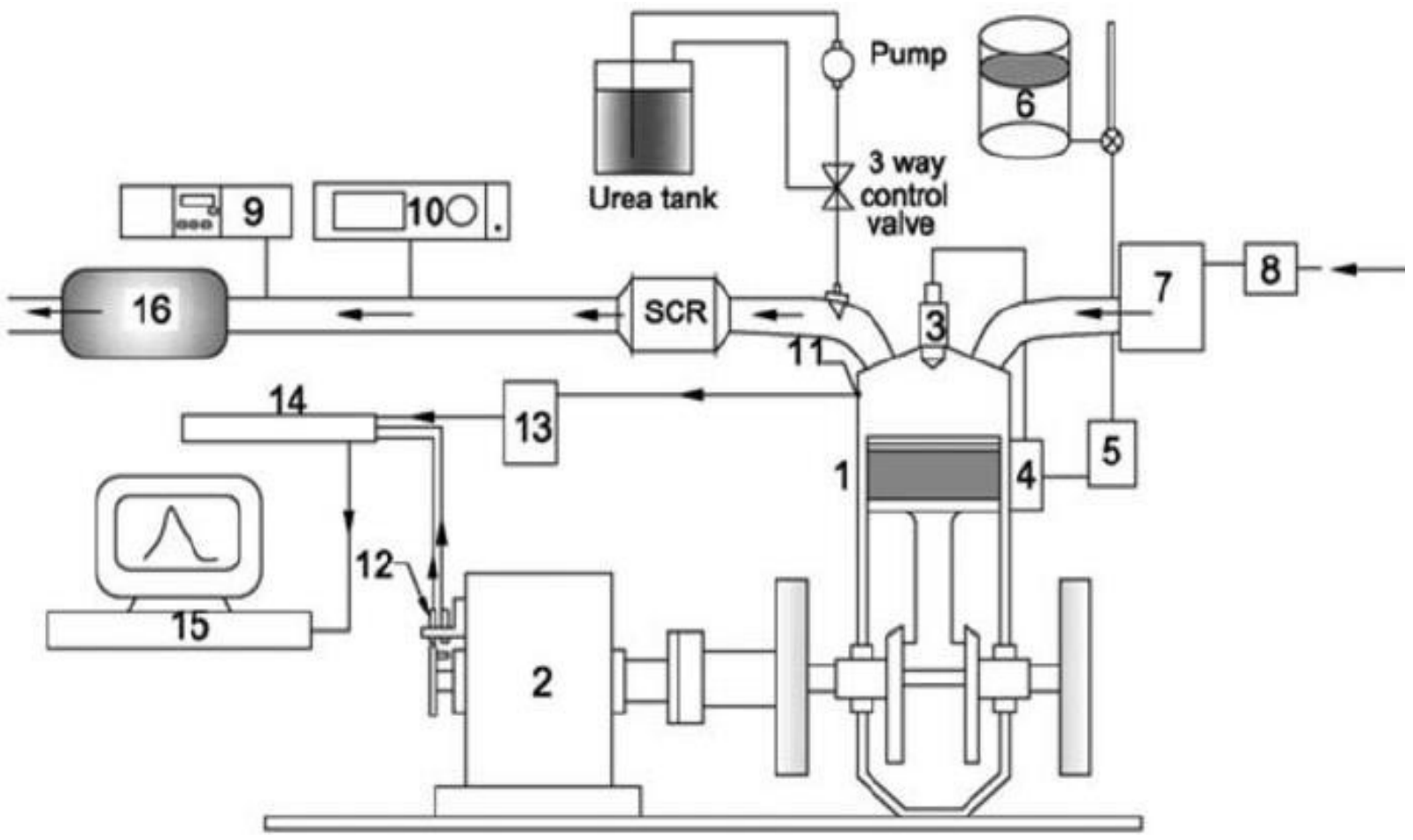

Figure 2.1: Schematic Diagram showing different parts of Experimental Engine Test Rig.

\begin{tabular}{|l|l|l|l|}
\hline 1. Kirloskar TV1 Engine & 2. Eddy Current Dynamometer & 3. Injector & 4.Fuel Pump \\
\hline 5. Fuel filter & 6.Fuel Tank & 7. Air stabilizing tank & 8.Air Filter \\
\hline 9. AVL Smoke Meter & 10.AVL Di-gas Analyzer & 11. Pressure Transducer & 12.TDC Encoder \\
\hline 13. Charge Amplifier & 14.Indi meter & 15. Computer Monitor & 16.Exhaust Silencer \\
\hline
\end{tabular}


Table 2.1: Fatty Acid Composition in Chicken Fat

\begin{tabular}{|c|l|c|}
\hline SL. No. & \multicolumn{1}{|c|}{ Fatty acid } & Composition (\%) \\
\hline 1. & Myristic 14:0 & 1 \\
\hline 2. & Palmitic 16:0 & 25 \\
\hline 3. & Palmitoleic 16:1 & 8 \\
\hline 4. & Stearic 18:0 & 6 \\
\hline 5. & Oleic 18:1 & 41 \\
\hline 6. & Linoleic $18: 2$ & 18 \\
\hline
\end{tabular}

Table 2.2: Properties of Waste Chicken fat Sample

\begin{tabular}{|c|l|l|}
\hline SL. No. & \multicolumn{1}{|c|}{ Fat Properties } & \multicolumn{1}{c|}{ Values } \\
\hline 1. & Acid value & $4.81(\mathrm{mg} \mathrm{KOH} / \mathrm{g})$ \\
\hline 2. & Moisture content & $0.32(\mathrm{wt} \%)$ \\
\hline 3. & Viscosity & $40.89\left(\mathrm{~mm}^{2} / \mathrm{s}\right)$ \\
\hline 4. & FFA $\%$ & 2.410 \\
\hline
\end{tabular}

Table 2.3: Characteristics of the Biodiesel Comparing with Petro-Diesel as per ASTM Standard

\begin{tabular}{|c|l|c|c|c|}
\hline SL. No. & \multicolumn{1}{|c|}{ Characteristics } & Petro-Diesel & B10 & B20 \\
\hline 1. & Acid value $(\mathrm{mg} / \mathrm{KOH} / \mathrm{g})$ & 0.50 & 0.412 & 0.441 \\
\hline 2. & Methyl ester content (\%) & -- & 87.5 & 99.6 \\
\hline 3. & $\begin{array}{l}\text { Calorific Value } \\
(\text { per MJ kg-1) }\end{array}$ & 42 & 41.88 & 44.62 \\
\hline 4. & Density $\left(\right.$ per kg m- $\left.{ }^{3}\right)$ & 870 & 866 & 889 \\
\hline 5. & $\begin{array}{l}\text { Kinematic Viscosity } \\
\left(@ 40^{\circ} \mathrm{C} / \mathrm{cSt}\right)\end{array}$ & 3.6 & 4.9 & 5.8 \\
\hline 6. & Flash Point $\left({ }^{\circ} \mathrm{C}\right)$ & 78 & 165 & 171 \\
\hline 7. & Fire Point $\left({ }^{\circ} \mathrm{C}\right)$ & 82 & 171 & 180 \\
\hline
\end{tabular}

Table 2.4: Technical specification of Engine

\begin{tabular}{|c|l|l|}
\hline SL. No. & \multicolumn{1}{|c|}{ Particulars } & \multicolumn{1}{c|}{ Specifications } \\
\hline 1. & Manufacturer & Kirloskar Oil Engines Ltd \\
\hline 2. & Model & TV-2 \\
\hline 3. & No of Cylinder & Two \\
\hline 4. & Type of Engine & $\begin{array}{l}\text { Vertical, 4-Stroke cycle, } \\
\text { Single acting }\end{array}$ \\
\hline 5. & Cooling & Water \\
\hline 6. & Fuel & Diesel \\
\hline 7. & HP & $16 \mathrm{HP}$ \\
\hline 8. & Starting & Hand Cranking \\
\hline 9. & Bore & $87.5 \mathrm{~mm}$ \\
\hline 10. & Stroke & $110 \mathrm{~mm}$ \\
\hline 11. & Cubic Capacity & $1322 \mathrm{cc}$ \\
\hline 12. & Nominal Compression Ratio & $17.5: 1$ \\
\hline 13. & Fuel Timing by Spill(BTDC) & 26 Deg \\
\hline 14. & Inlet valve opens BTDC & $4.5 \mathrm{Deg}$ \\
\hline 15. & Inlet valve closes ATDC & $35.5 \mathrm{Deg}$ \\
\hline 16. & Exhaust valve opens BBDC & $35.5 \mathrm{Deg}$ \\
\hline 17. & Exhaust valve closes ATDC & $4.5 \mathrm{Deg}$ \\
\hline 18. & Valve Clearance Inlet & $0.18 \mathrm{~mm}$ \\
\hline 19. & Valve Clearance Exhaust & $0.20 \mathrm{~mm}$ \\
\hline & & \\
\hline
\end{tabular}




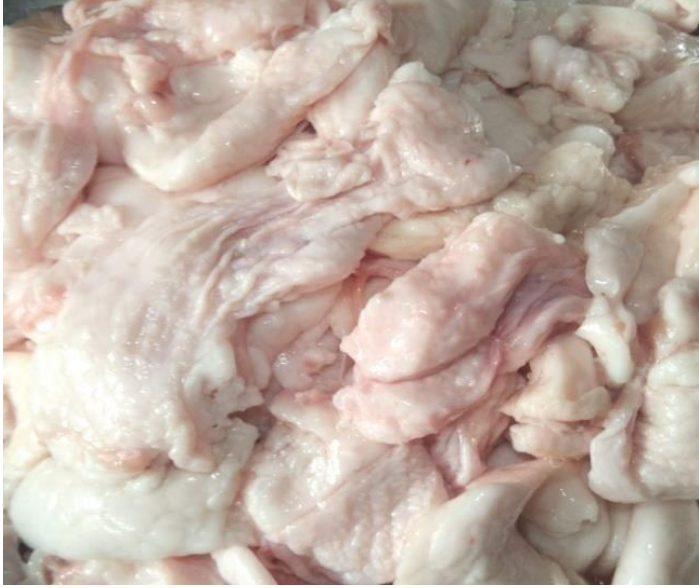

A

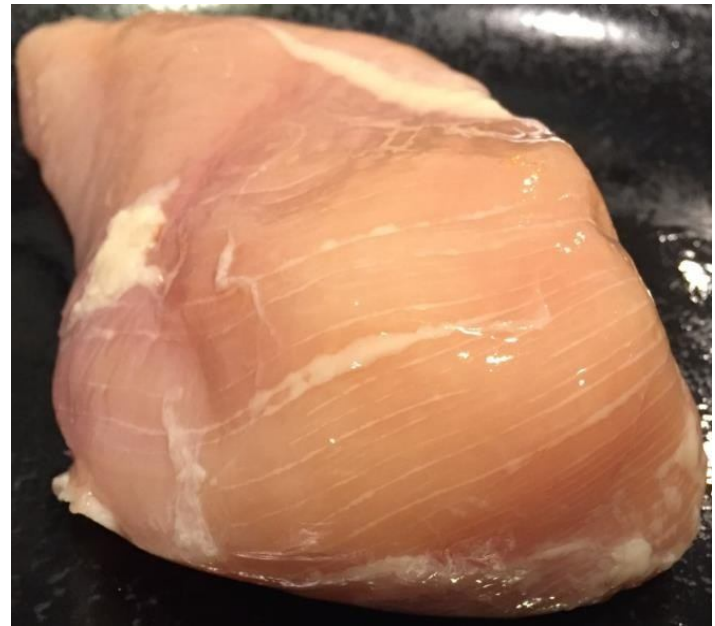

C

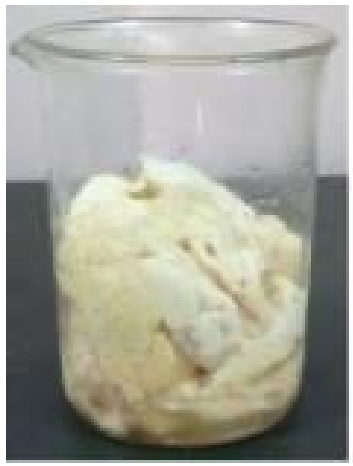

E1

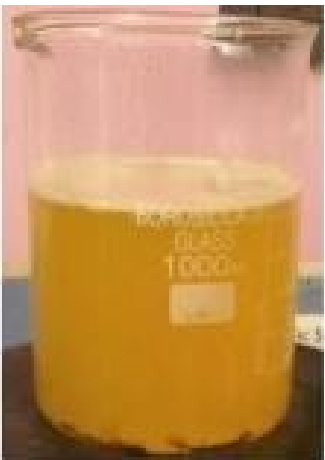

E2

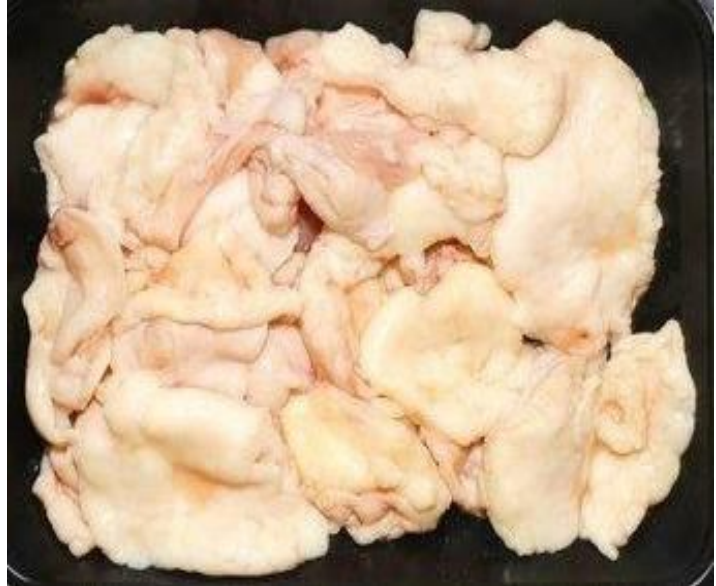

B

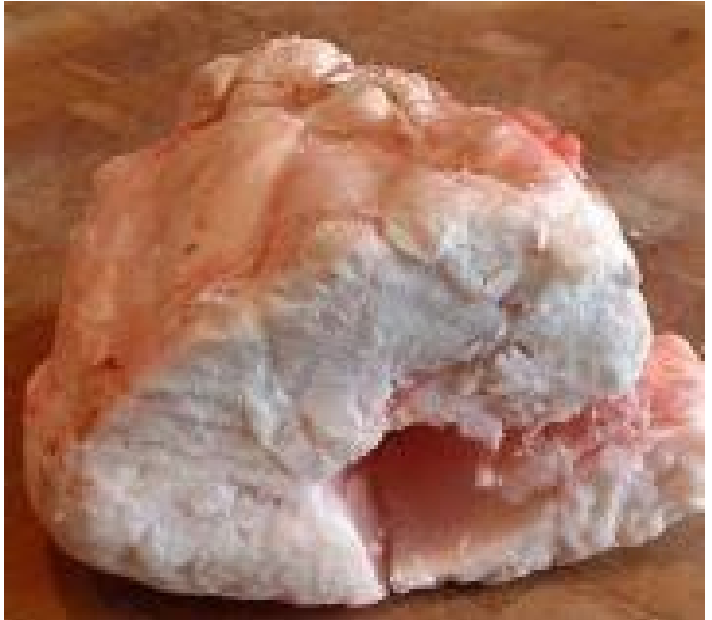

D

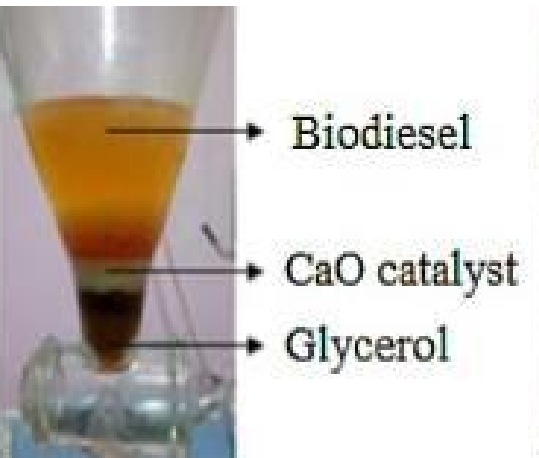

E3

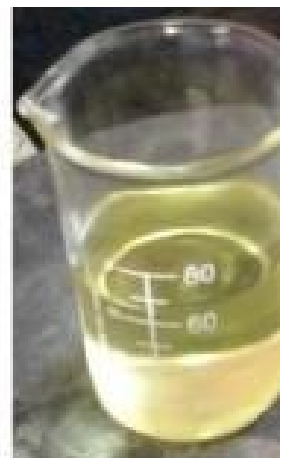

E4

Figure 2.2: Production of Biodiesel from Waste Chicken Fat (WCF) Samples

Figure A\& B: Waste Chicken fat samples, C: Exercised Raw Chicken meat, D: Processed chicken fat Figure E1: Chicken fat subjected for Oil, E2: WCF Oil, E3: Separation of Biodiesel and E4: Pure Biodiesel 

Blends Of Wastes Chicken Fat Biodiesel with Exhaust Gas Recirculation

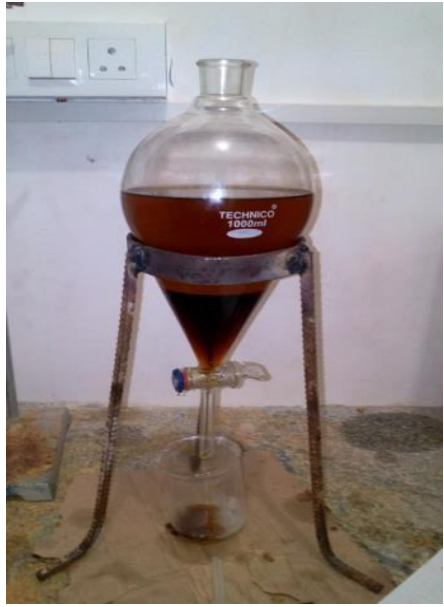

F

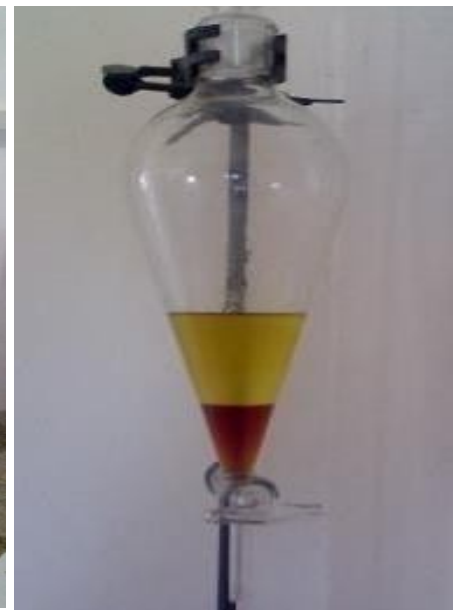

G

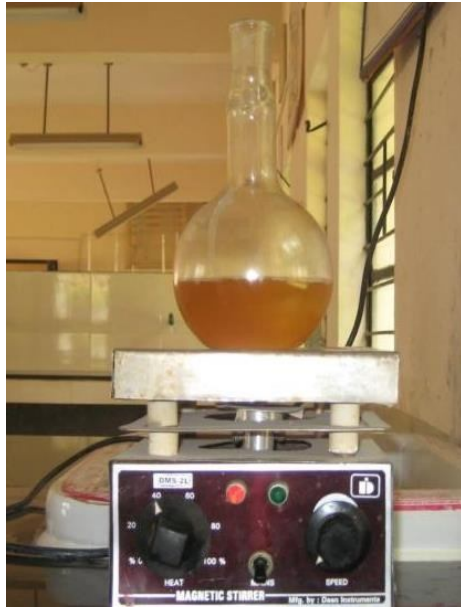

$\mathbf{H}$

Figure F: Heating of ME Figure G: Separation of Biodiesel Figure H: Glycerine Separation.

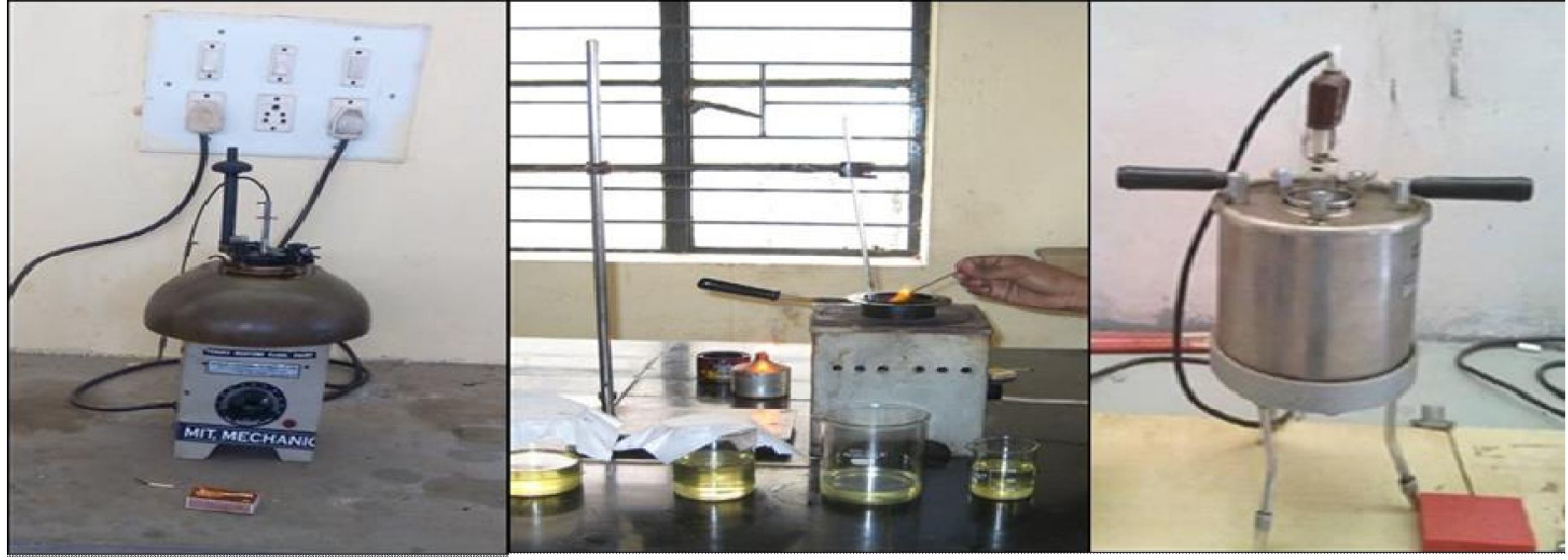

I

$\mathbf{K}$

Figure I: Viscometer and Figure J \& K: Figure Flash Point \& Fire Point Analyzer.

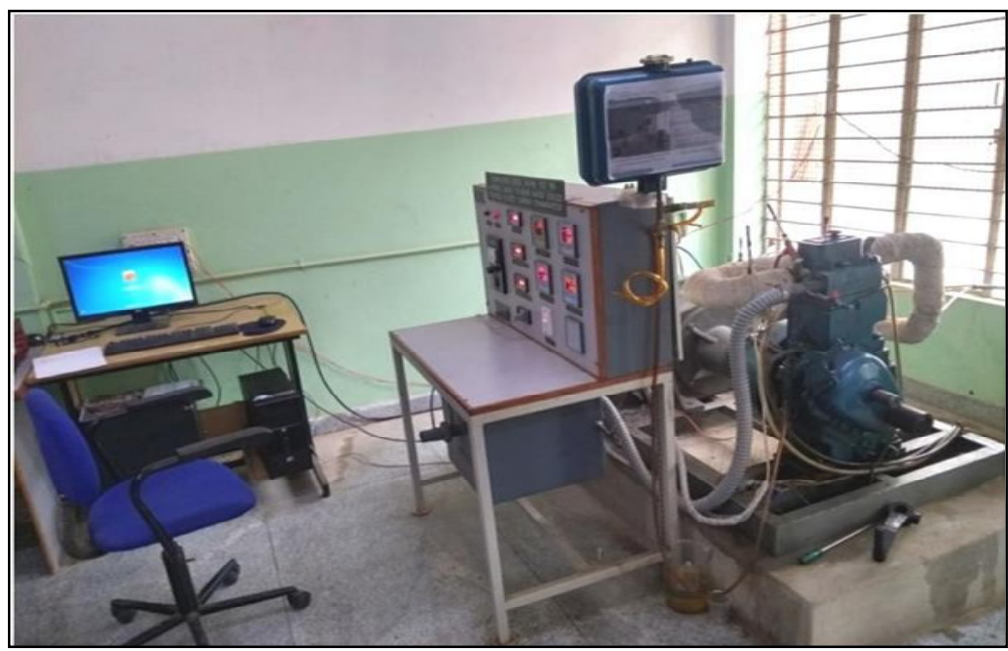

Figure 2.3: Characterization of WCF Biodiesel.

Figure L.Computerized4-Stroke, Single Cylinder, Water Cooled Diesel Engine. 


\section{RESULTS AND DISCUSSIONS}

In the present study, it was confirmed that, the waste chicken fat samples are potential resource to convert into bio-diesel; due to its high amount of fatty acid composition and crude protein values (Table 2.1). The extracted fat from waste chicken meat samples was found to be significant and the FFA was reduced positively via pre-processing. The result on properties of chicken fat was represented in the Table.2.2. Then, the fat (purified) was subjected for transesterification to achieve optimized biodiesel and the pure biodiesel after washing was evaluated for its properties as per ASTM standard (Table. 2.3).

The measured parameters were all in an acceptable range therefore, the blending ratio of WCF biodiesel was tested for its efficacy with a pre-designed experimental engine test rig with respect to performance with optimization and emission parameters coupled with EGR (Table 2.3 and Table 2.4). Hence, it is evident from the parametric analysis that, the properties of the WCF biodiesel is found to be incredibly similar to the petro-diesel which we use in automobile in the current perspective $[18,23]$.

\section{Engine Performance Characteristics}

The performance and its optimization followed by emission characteristics of CI Engine fuelled with blends of Biodiesel derived from Waste chicken Fat (WCF) and petro-diesel was comparatively evaluated with exhaust gas recirculation (EGR) at various loading conditions. The CI engine was tested under constant speed of 1800rpm with varying load from zero percentage loads to $100 \%$ load. In this section various performance characteristics like Specific fuel consumption and Brake thermal efficiency were discussed.

The Brake Thermal Efficiency (BTE) and Brake Specific Fuel Consumptions (BSFC) for waste chicken fat biodiesel blend with exhaust gas recirculation are clearly represented (Fig.3.1 \& 3.2). The brake thermal efficiency (BTE) with petrodiesel fuel was found to be slightly lower as compared to both B10 and B20 blending ratios at all the load operations. The BTE at full load for B20 followed by petro-diesel was found to be maximum $37.26 \%$ due to the higher calorific value than petro diesel.

It was observed that, the BTE increases appreciably at the constant EGR flow rate (30\%), when the exhaust gas was introduced into a combustion chamber where, the deficiency in required oxygen content results in the reduction of combustion that leads to decrease in BTE [4, 9,22].

The BTE was increased by $3.2 \%$ at B20 when compared to petro-diesel with the EGR flow rate $30 \%$ respectively. The BSFC of the biodiesel blending ratios was slightly lower (7.1\%) than the petro-diesel. It was due to the better calorific value of the biodiesel and it was increased at EGR flow rate which leads to complete combustion of biodiesel. The observations have been emphasized hereunder $[8,14,16]$. 


\section{Brake Thermal Efficiency}

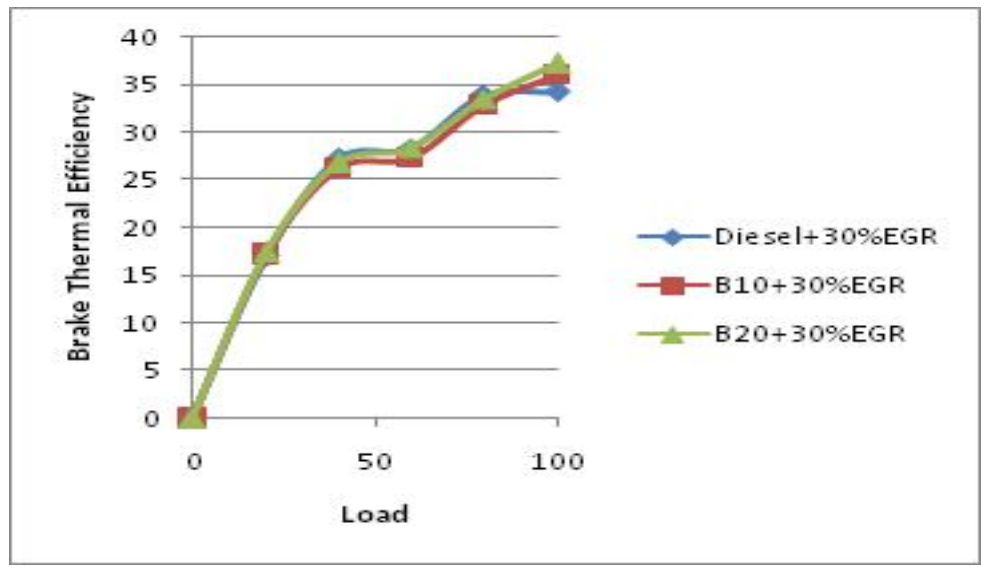

Figure 3.1: Load Vs BTE.

From the figure.3.1 it has been observed that B10 and B20, the BTE is higher than the neat diesel. The maximum BTE is accounted for B20 (37.26\%) and minimum is observed for diesel (34.24\%). This shows that there is $3.2 \%$ increase in BTE of B20 when compared with diesel under 30\% EGR. This is because of better air fuel mixing, improved combustion due to biodiesel [5].

\section{Specific Fuel Consumption}

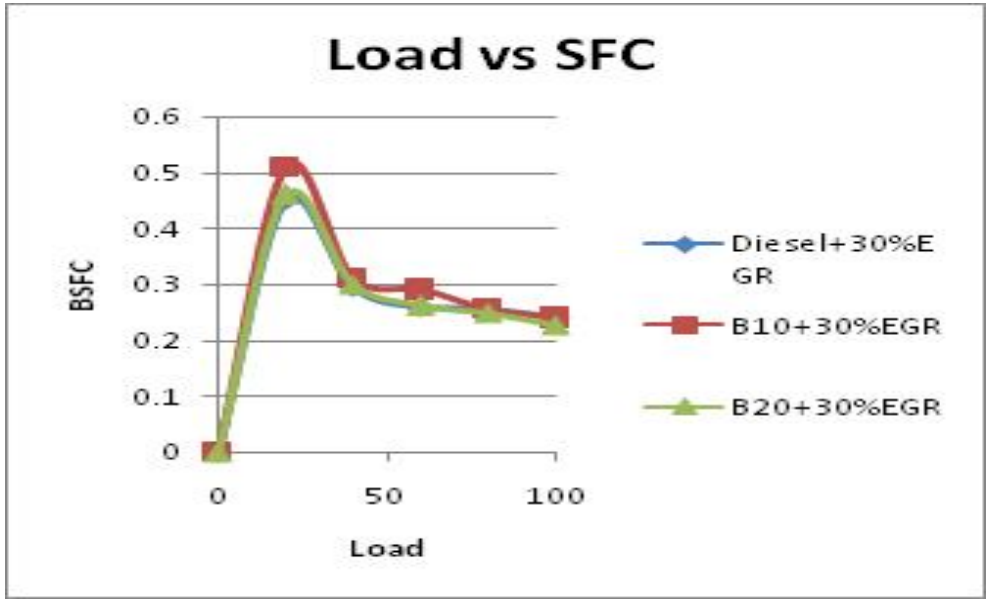

Figure: 3.2: Load Vs SFC.

Figure.3.2 shows that SFC variations with respect to load applied for all blended fuels. It is clear from the graph that SFC decreases with increase in load. The maximum SFC is observed for diesel $(0.2432 \mathrm{Kg} / \mathrm{kw}-\mathrm{hr})$ and minimum for B20 $(0.228 \mathrm{Kg} / \mathrm{kw}-\mathrm{hr})$. So there is $7.1 \%$ decrease in SFC of B20 blend. Lower the SFC it clearly indicates improvement in performance [6].

\section{Engine Exhaust Emission Characteristics}

The emission characteristics such as; CO, UBHC and NOx emissions for the blends of Waste Chicken Fat (WCF) biodiesel in comparison with petro-diesel at variable loads was evaluated. 
The lower hydrocarbon emission was observed in the WCF biodiesel as compared to petro-diesel which may be due to presence of superior oxygen content present in the WCF biodiesel as a result of which the improved combustion of the fuel was observed. It was also noticed that, the hydrocarbon emission was decreases with the variable loads and at $30 \%$ EGR flow rate which is because of adequate amount of oxygen available for combustion process (Fig.3.5) . In case of petrodiesel, higher hydrocarbon level was observed which was due to the lack of oxygen is responsible for reduced oxidation rate, which leads to incomplete combustion, hence higher unburned hydrocarbon emissions was noticed $[6,7,10]$.

The considerable decrease of carbon monoxide (CO) with EGR flow rate was noticed in comparison with petrodiesel. However, the emission of $\mathrm{CO}$ was found to be relatively lower due to the molar oxygen available in the blending fractions (B20) of WCF biodiesel at all loads (Fig.3.3).

In addition, there was a decreasing trend with respect to reaction speed and in-cylinder temperature at the EGR flow rate. Whereas, in case of petro-diesel, more exhaust gas reduces the $\mathrm{O}_{2}$ concentration which may leads to decline in the oxidation reaction and produces more $\mathrm{CO}$ emission (Fig.3.5).

Further, it was observed that, the reduced NOx emissions (value) in WCF biodiesel blending fractions at all loads as compared to petro-diesel, this was due to the superior combustion reaction that produces less $\mathrm{HC}, \mathrm{CO}$ and smoke. But, the NOx emission tends to reduce more significantly with the EGR flow rate (Fig.3.4). This is due to rise in total heat capacity of the working gases by EGR that in turn lowers the elevated peak temperature. Thereby, the replacement of the intake of air by $\mathrm{N}_{2}$ reduces the NOx production because of the decreased oxygen concentration in the intake gas $[10,17]$.

However, replacing the intake air with $\mathrm{CO}_{2}$ and water vapor reduces NOx production to a greater extent than with $\mathrm{N}_{2}$ due to $\mathrm{CO}_{2}$ and water vapor is that these gases have a higher specific heat than $\mathrm{N}_{2}$ was $41.4,36.0$, and $29.2 \mathrm{~J} / \mathrm{mol} \mathrm{K}$ (at $400 \mathrm{~K}$ ) for $\mathrm{CO}_{2}$, water vapor, and N2, respectively. Around 25\% reduction EGR in NO emission was observed for B20 fuel blend with 30\% EGR when compared to the emission without EGR approach [17, 23].

Finally it was also observed that, the smoke emission was less for WCF biodiesel when compared to petro-diesel due to improved combustion. As a whole, higher amount of smoke emission was observed when the engine is operated with EGR when compared without EGR. In case of petro-diesel, EGR reduces availability of oxygen for combustion of fuel, which results in relatively incomplete combustion and increased formation of particulate matter and reducing NOx emissions from CI engine [12, 20-24, 27].

\section{Carbon Monoxide}

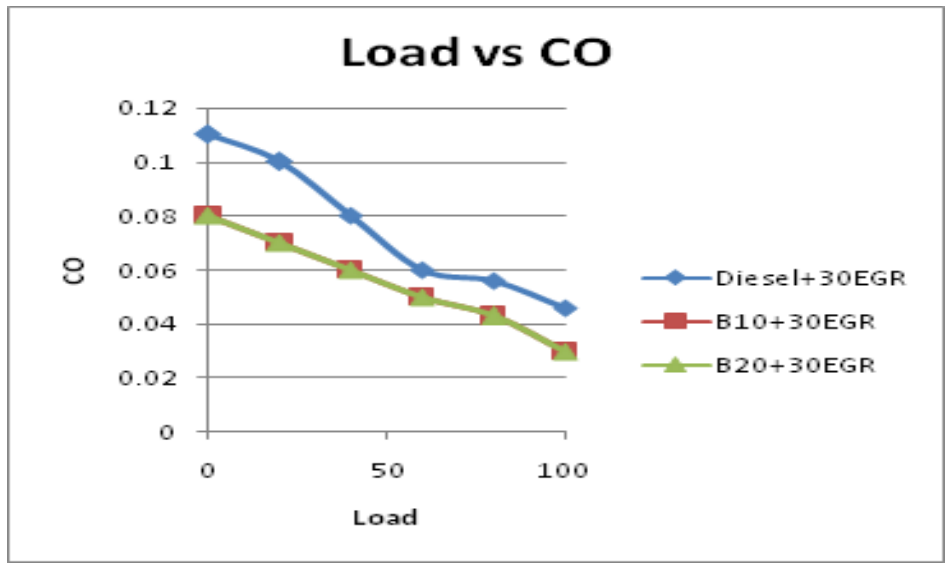

Figure 3.3: Load Vs CO. 
Figure.3.3 shows that variation of emission of CO with respect to load at 30\% EGR. The graph clearly shows the decrease of $\mathrm{CO}$ emission by using biodiesel blends compared to neat diesel. The $\mathrm{CO}$ emission is maximum for diesel and minimum for B20. From the graph it is clear that, the emission of CO in B20 is reduced by $16.66 \%$ compared to diesel. This is because of the fine atomization and oxygen content in the fuel which results in complete combustion [22-24].

\section{Nitrogen Oxides}

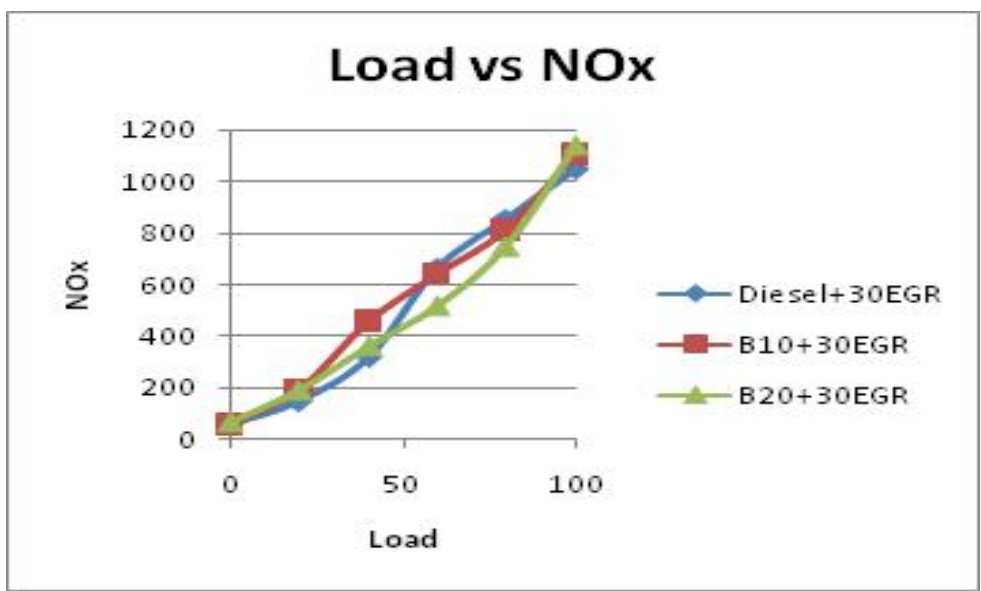

Figure 3.4: Load Vs NOx.

Figure.3.4 shows that, the variations of NOx emission with respect to variable load, the nitrogen reacts with oxygen only at high temperature and pressure, due to increases in combustion rate results high temperature in cylinder, it leads to reaction of nitrogen with oxygen and form nitrogen oxides and NOx emission increases with the temperature raise. Reduction NOx is done by using EGR. It clearly shows from the graph using EGR reduces the NOx emissions at full load, where it clearly shows for B20 (1142PPM) and diesel (1048ppm) respectively [17, 22, 24, 26].

\section{Un-burnt Hydrocarbon}

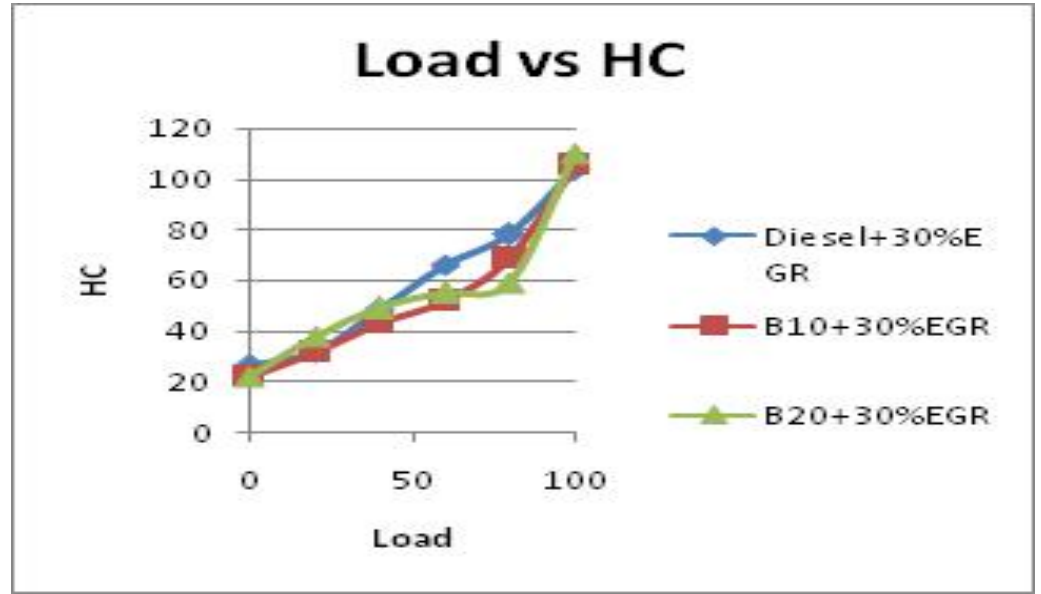

Figure 3.5: Load Vs UBHC. 
Figure 3.5 shows that variation of $\mathrm{HC}$ with respect to load. At all loads the $\mathrm{HC}$ emission is low for all blended fuels compared to neat diesel. The maximum and minimum HC emissions at full load are observed for diesel (112 ppm) and B20 $(104 \mathrm{ppm})$ respectively $[25,26,28]$.

\section{CONCLUSIONS}

From the experimental investigation, the generated data on Performance and emission of CI diesel engine with test fuels, the following conclusions are made.

- The maximum BTE is accounted for B20 CFO and minimum is observed for diesel. This showsthat there is increase in BTE for B20 CFO compared to diesel. We can observe that, using EGR there is a slight reduction in the thermal efficiency.

- The biodiesel which provide oxygen for complete combustion reduces the emission of CO and UBHC, However we can see NOx is increased for B20CFO due to high oxygen content, increased cylinder pressure and complete combustion.

- $\quad$ EGR reduces the NOx and UBHC emission.

- Finally, it can be concluded that, the engine interacted with CWF biodiesel coupled with EGR plays an important role in controlling emissions apart from improving the overall performance of the engine and bio-fuel.

\section{AKNOWLEDGEMENT}

The first authors acknowledge the Authorities of Research Centre, Ghousia College of Engineering, Ramanagara, Karnataka followed by Dept. of Mechanical Engineering, Vivekananda Institute of Technology, Bengaluru, Karnataka for providing the basic facilities to carry-out this Research works. My grateful thanks to the Research Supervisors, Dr. H V. Byregowda Dept. of Mechanical Engineering, Ghousia College of Engineering, Ramanagara and Dr.G.Panduranga Murthy, Dept. of Engineering Chemistry, Maharaja Institute of Technology Thandavapura, Mysuru district, Karnataka for their incessant inputs, guidance and encouragement etc. for completion of this research successfully. Also thank the authorities of Visvesvaraya Technological University, Belagavi, Karnataka, India for facilitating my Research programme leading PhD degree.

\section{REFERENCES}

1. Adewale, P., Dumont, M.-J., and Ngadi, M. 2015. Recent trends of biodiesel production from animal fat wastes and associated production techniques. Renewable and Sustainable Energy Reviews, 45, 574-588. doi:10.1016/j.rser.2015.02.039

2. Abdoli, M. A, Mohamadi, F, Ghobadian, and Fayyazi, E. 2014. Effective Parameters on Biodiesel Production from Feather Fat Oil as a Cost-Effective Feedstock, International Journal of Environment. 8(1),139-148.

3. Altaie MA, Janius RB, Rashid U, Taufiq-Yap YH, Yunus R, Zakaria R, et al. 2015. Performance and exhaust emission characteristics of direct-injection diesel engine fueled with enriched biodiesel. Energy Convers. Manage; 106: 365-72.

4. Aleem Amber, Aslam Fakhra, and Shahid Ammara, Quantification of Fat in Chicken's Feather Meal for its Conversion into Biodiesel. 2014. International Research Journal of Environment Sciences, 3 (6), 2014, 67-74. 
5. Anurag K B, Akhilprasad, Anoop K V, Abinvarghese, Anvarsadath and Dr. G. Kalivarathan.2016. Experimental Investigation of Blends of esterified Coconut Oil and Sunflower Oil in a 4 Stroke CI Engine, International Research Journal of Engineering and Technology, 3 (2), 1526-1535.

6. Ashok, B., Nanthagopal, K. Rayapati Subbarao, Ajith Johny, Aravind Mohan. 2017. Experimental studies on the effect of metal oxide and antioxidant additives with Calophyllum Inophyllum Methyl ester in compression ignition engine. Journal of Cleaner Production, 10.1016/j.jclepro. 2017.08.050 S0959-6526(17) 31768-7.

7. Attia, A.M.A. Hassaneen, A.E. 2016. Influence of diesel fuel blended with biodiesel produced from waste cooking oil on diesel engine performance, Fuel; 167; 316-328.

8. Chiranjeeva Rao Seela, B. Ravi Sankar,D. Kishore \& M. V.S. Babu. 2019. Experimental analysis on a DI diesel engine with cerium-oxide-added Mahua methyl ester blends, International Journal of Ambient Energy, 40:1, 4953, DOI: 10.1080/01430750.2017.1360203.

9. Darunde Dhiraj S. 1, Prof. Deshmukh Mangesh M, Biodiesel Production from Animal Fats and its Impact on the Diesel Engine with Ethanol-Diesel Blends: A Review, International Journal of Emerging Technology and Advanced Engineering, 2(10), 2012, 179-185.

10. Debbarma, S., Misra, R. D. 2017. Effects of Iron Nanoparticles Blended Biodiesel on the Performance and Emission Characteristics of a Diesel Engine. Journal of Energy Resources Technology, ASME, Vol. 139 / 042212-1

11. Gerhard Knothe, Kevin R. Steidley. 2018. The effect of metals and metal oxides on biodiesel oxidative stability from promotion to inhibition, Fuel Processing Technology; 177 (2018) 75-80.

12. Jiaqiang E, Minhhieu Pham, Effect of different technologies on combustion and emissions of the diesel engine fuelled with biodiesel, Renewable and Sustainable Energy Reviews 80 (2017) 620-647.

13. Jorge Ramírez-Ortiz, Merced Martínez Rosales, Horacio, and Flores Zúñiga. 2014. International Journal of Chemical, Molecular, Nuclear, Materials and Metallurgical Engineering, 8(9), 2014, 112-119.

14. Kambiz Tahvildari A., Narges Davari B., Mohammadreza Allahgholi Ghasri C, and Masoomeh Behrourzinavid D, Biodiesel Production from Waste Chicken Fat Based Sources, International Journal of Chemical, Molecular, Nuclear, Materials and Metallurgical Engineering, 5(7), 2011, 562-564.

15. Man, X.J. Cheung, C.S. Ning, Z. 2015. Effect of diesel engine operating conditions on the particulate size, nanostructure and oxidation properties when using wasting cooking oil biodiesel, Energy Procedia 66 (2015) 37-40.

16. Maryem Belgharza, EL habib EL Azzouzi, Meryem Kitane, Hind El Bouzaidi, Yahya, Idrissi, and Mohamed Alaoui El Belghiti. 2014. Study of Manufacturing Biodiesel from Waste Animal Fats (chicken) in Morocco, Journal of Chemical and Pharmaceutical Research, 6(12), 2014, 844-849.

17. Mohamed M. Musthafa, Ashok Kumar, T. Mohan raj, T. R and Chandramouli, A. 2018. Comparative study on performance, combustion and emission characteristics of diesel engine fuelled by biodiesel blends with and without an additive. Fuel; 225 (2018) 343-348.

18. Nuhu, S and Kovo A.S. 2015 Production and Characterization of Biodiesel from Chicken Fat, Journal of Agricultural Science, 5(1), 22-29.

19. Rajesh Mehta, Dale, R.G. 2007. True metabolizable energy of feather meal, Journal of Applied Poultry Research; 331-334 2007. 
20. Rolvin D'Silvaa, Binu K.G, Thirumaleshwara Bhat. 2015. Performance and Emission characteristics of a C.I. Engine fuelled with diesel and $\mathrm{TiO}_{2}$ nanoparticles as fuel additive”. Materials Today: Proceedings 2; 3728 - 3735.

21. Sahara, Sana Sadafb, Javed Iqbala, Inam Ullahd. 2018. Biodiesel production from waste cooking oil: An efficient technique to convert waste into biodiesel", Sustainable Cities and Society 41: 220-226.

22. Selvallavarasi Panneerselvam, R. Parthiban, and Dr. Lima Rose Miranda. 2011. Poultry Fat a Cheap and Viable Source for Biodiesel Production, International Conference on Environmental Science and Technology, 6(1),144-149.

23. Verma, P., and M. P. Sharma. 2015. Performance and emission characteristics of biodiesel fuelled diesel engines. International Journal of Renewable Energy Research 5 (1):245-50.

24. Vinuothan, K., P. R. Sequeira, and R. Veneeth. 2016. Investigations on the performance and emission characteristics of CI engine using different blends of waste cooking oil methyl ester - ethanol - diesel oil. Energy and Power 6 (1A):28-32.

25. Yang, C., K. He, Y. Хue, Y. Li, H. Lin, and H. Sheng. 2018. Factors affecting the cold flow properties of biodiesel: Fatty acid esters. Energy Sources, Part A: Recovery, Utilization, and Environmental Effects 40 (5):516-22.

26. Yekta Hemmat, Barat Ghobadian, Mohammad Loghavi, Saadat Kamgar, and Ebrahim Fayyazi.2013. Biodiesel Fuel Production from Residual Animal Fat as an inedible and inexpensive feedstock, International Research Journal of Applied and Basic Sciences, 5(1), 84-91.

27. Wiggers, V.,Wisniewski, JrA, Madureira L, Barros A, Meier H. 2009. Bio-fuels from waste fish oil pyrolysis: continuous production in a pilot plant. Fuel; 88:2135-41.

28. Zheng S, Kates M, Dubé MA, McLean DD. 2006. Acid-catalyzed production of biodiesel from waste frying oil. Biomass Bioenergy; 30:267-72. 